\title{
Reoperations and survival after primary repair of congenital heart defects in children
}

\author{
James L. Monro, FRCS \\ Christos Alexiou, FRCS ${ }^{a}$ \\ Anthony P. Salmon, FRCP \\ Barry R. Keeton, FRCPb
}

Objective: The objective of this article is to evaluate the incidence of reoperation and the associated risk and survival after primary repair of congenital heart defects using cardiopulmonary bypass in children.

Methods: We present a retrospective analysis of 1220 consecutive children under 16 years [649 (53\%) under 1 year] operated on between 1976 and 2001 by 1 surgeon (J.L.M.).

Results: The early (30-day) mortality was $6.9 \%$; 171 patients had 206 reoperations. The early mortality for the first reoperation was $10.4 \%$ and for second reoperation, $3.8 \%$. Of the first-time reoperations $63 \%$ were inevitable, $15 \%$ were planned, and $22 \%$ were unexpected. The overall 20 -year freedom from reoperation was $83 \%$ and survival (including early mortality) was $86 \%$. The 10 -year freedom from reoperation and survival, respectively, was as follows: aortic valvotomy, $77 \%$ and $92 \%$; pulmonary valvotomy, $90 \%$ and $95 \%$; atrial septal defect, $99 \%$ and $100 \%$; partial atrioventricular septal defect (AVSD), 81\% and 94\%; complete AVSD, 74\% and $70 \%$; VSD, 95\% and 97\%; double-outlet right ventricle, $66 \%$ and $68 \%$; truncus arteriosus, $54 \%$ and $71 \%$; Mustard, $85 \%$ and $86 \%$; arterial switch, $78 \%$ and $74 \%$; Fontan, $77 \%$ and $66 \%$; Fallot, $91 \%$ and $93 \%$; and total anomalous pulmonary venous drainage, $89 \%$ and $84 \%$. Of those undergoing aortic valvotomy, $53 \%$ were infants, but when aortic valve replacement became necessary an adult valve could be inserted. Introduction of the total cavopulmonary connection to the Fontan procedure in 1990 with prior cavopulmonary anastomoses has greatly improved outcome, with only 1 reoperation and no deaths since then. Patients with AVSD required 12 reoperations for mitral regurgitation, mostly through the "cleft," the closure of which in the past 5 years has provided promising results.

Conclusions: The majority of reoperations after repair of congenital heart defects in children are inevitable, and their incidence varies for different types of procedures. These findings will help in informing parents about the possible outcome of surgery, but the introduction of newer techniques may reduce the need for reoperation further. The survival is encouraging.

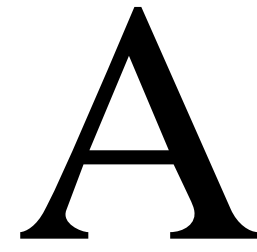

lthough results of surgery for congenital heart disease are now good, apart from some simpler conditions, for example, atrial (ASD) and ventricular septal defect (VSD), it has become apparent that many children may require further surgery. Therefore, to describe the initial operation as a "repair" rather than correction seems to be appropriate.

Increasingly, parents need more information about the operations their children are to undergo, not only the immediate risks but also the long-term prospects including the need for further intervention. 
The main purpose of this study was to determine how many patients require reoperation, when, why, and the outcome. The reasons for reoperation are classified into planned, inevitable, and unexpected. As surgeons, we probably cannot do much about the inevitable group, but we must try to minimize the unexpected group.

\section{Methods}

\section{Study Population}

Southampton covers a circumscribed area in the south of England with a population of about 3 to 4 million. Virtually all children within this area would come to this unit, although some patients come from further afield and from abroad.

Between 1976 and 2001, a total of 1220 consecutive children (mean age $32.2 \pm 34.5$ months, range 1 day to 15 years) had a first-time cardiac operation with cardiopulmonary bypass (CPB) performed or supervised by 1 surgeon (J.L.M.). There were 581 girls $(48 \%)$ and 639 boys $(52 \%)$ with a mean age of $32.2 \pm 34.5$ months (range 1 day to 16 years). Of these patients, $649(53 \%)$ were infants (up to 1 year old).

\section{Patient Demographics}

Data on early (30-day) death and the incidence of reoperation were collected retrospectively from the department's computerized database. Patients who had had previous surgery without the use of CPB were included, but patients who had had a previous CPB operation elsewhere or by the principal surgeon before 1976 were excluded. Patients were grouped according to their first operation on bypass, and "miscellaneous" was defined as those groups with less than 15 patients (appendix).

\section{Technical Considerations}

All operations (apart from a few ASDs closed through the right side of the chest) were performed through the midline. For the first 15 years of this series the great majority of infants were operated on with the use of deep hypothermia and circulatory arrest. This has become increasingly infrequent and now circulatory arrest would be used only for short periods, for example, in repair of an interrupted aortic arch. Otherwise, standard CPB techniques were used with membrane oxygenators since 1987. Crystalloid cardioplegia has been used since 1978 and cold blood cardioplegia for the past 7 years. Standard operative procedures were used as previously described. ${ }^{1-4}$

\section{Reoperations}

Reoperations were considered to be those requiring CPB. They could be classified into the following groups:

1. Planned, where the reoperation was a staged part of a planned strategy (eg, a Fontan-type procedure after a previous cavopulmonary anastomosis).

2. Inevitable, where it is known that the initial operation is part of a progressive disease process (eg, late valve replacement after aortic valvotomy or right ventricular outflow tract conduit replacement).

3. Unexpected, which included any reoperation performed within 30 days or ones that could not be predicted and one would hope would not happen (eg, closure of a residual
VSD, or repair of pulmonary artery stenosis after a switch procedure for transposition of the great arteries [TGA]).

\section{Follow-up}

Patients were followed up by the pediatric cardiologists, both in the main unit and in peripheral clinics. If all was well, patients with the simplest conditions such as ASDs and VSDs would be discharged. All others would be continually observed, and, if patients were well, with increasing intervals between appointments. Follow-up of the patients has therefore been obtained by contacting the pediatric cardiologists, other physicians, or the patient's general practitioner. With the exception of 3 cases, we performed all the reoperations.

\section{Statistics}

Continuous variables are expressed as means \pm SD and proportions as percentages. Freedom from reoperation and survival ( \pm SEM) were calculated by the product-limit method of Kaplan and Meier and include both early mortality and reoperations performed within the same hospital admission after the initial repair. Statistical analysis was done with the statistical package SPSS PC (version 8.0; SPSS Inc, Chicago, Ill).

\section{Results}

There have been 85 early deaths, giving an overall operative mortality of $6.9 \%$. Sixty-eight additional patients died after their discharge from the hospital (the 20-year Kaplan-Meier survival, including the operative mortality, being $86 \pm 1 \%$ ). Operative mortality and Kaplan-Meier 10- or 20-year survival for each procedure are shown in Table 1, together with the number (and category) of reoperations and associated early mortality for each condition.

A total of 171 patients underwent 1 reoperation, of which 108 were inevitable, 26 were planned, and 37 were unexpected. The types of unexpected reoperations and their indications are shown in Table 2. Twenty-eight patients had a second reoperation (21 inevitable, 2 planned, and 5 unexpected), 5 patients had a third operation (4 inevitable and 1 unexpected), and 2 patients had a fourth reoperation (1 inevitable and 1 unexpected). Overall early mortality at first reoperation was $10.4 \%$ and it was $3.8 \%$ at second reoperation. There have been no deaths after the third or fourth reoperations.

Overall 20-year freedom from any reoperation was $83 \%$ $\pm 1 \%$ and from inevitable, planned, and unexpected first reoperation this was $88 \% \pm 1 \%, 97 \% \pm 0.5 \%$, and $96 \% \pm$ $0.6 \%$, respectively. Kaplan-Meier freedom from first reoperation (any type, inevitable, planned, and unexpected) for each procedure is shown in Table 3. Freedom from a second reoperation for all patients at 10 years was $98 \% \pm 4 \%$ and it was $97 \% \pm 0.6 \%$ at 20 years.

The types of reoperations according to the original procedure are described in more detail below. 
TABLE 1. Early mortality, first reoperations, mortality at first reoperation, and Kaplan-Meier survival

\begin{tabular}{|c|c|c|c|c|c|}
\hline Procedure & No. & Early deaths & First reoperation & $\begin{array}{l}\text { Death at first } \\
\text { reoperation }\end{array}$ & $\begin{array}{c}\text { Ten year survival } \\
(\%)\end{array}$ \\
\hline Aortic valvotomy & 62 & $2(3.2 \%)$ & $14(I)$ & $2(14.2 \%)$ & $92 \pm 3$ \\
\hline $\begin{array}{l}\text { Resection subaortic } \\
\text { stenosis }\end{array}$ & 20 & - & $4(I)$ & - & 100 \\
\hline Pulmonary valvotomy & 66 & $3(4.5 \%)$ & $8(7-I, I-P)$ & - & $\begin{array}{l}95 \pm 2 \\
(91 \pm 4)^{*}\end{array}$ \\
\hline ASD closure & 157 & - & $2(I)$ & - & 100 \\
\hline Partial AVSD repair & 40 & - & $8(7-I, 1-U)$ & - & $94 \pm 4$ \\
\hline Complete AVSD repair & 44 & $8(18 \%)$ & $9(7-I, 2-U)$ & - & $70 \pm 7$ \\
\hline VSD closure & 237 & $3(1.2 \%)$ & $13(10-I, 3-U)$ & $1(7.7 \%)$ & $\begin{array}{c}97 \pm 1 \\
(93 \pm 2)\end{array}$ \\
\hline VSD and PS & 29 & $2(7 \%)$ & - & - & $93 \pm 5$ \\
\hline DORV repair & 25 & $5(20 \%)$ & $6(4-I, 2-U)$ & $1(17 \%)$ & $68 \pm 10$ \\
\hline Truncus arteriosus repair & 28 & $7(25 \%)$ & $13(\mathrm{I})$ & $1(7.7 \%)$ & $71 \pm 9$ \\
\hline Mustard for TGA & 56 & $3(5.4 \%)$ & $8(3-I, 5-U)$ & $1(12.5 \%)$ & $\begin{array}{c}86 \pm 5 \\
(80 \pm 5)\end{array}$ \\
\hline Switch for TGA & 38 & $8(21 \%)$ & $7(U)$ & $1(14.2 \%)$ & $74 \pm 7$ \\
\hline Fontan procedure & 33 & $6(18 \%)$ & 8 (5-I, 1-P, & - & $66 \pm 8$ \\
\hline TOF repair & 177 & $8(4.5 \%)$ & $19(12-I, 7-U)$ & $2(10.5 \%)$ & $\begin{array}{c}93 \pm 2 \\
(93 \pm 2)\end{array}$ \\
\hline PA and VSD repair & 31 & $3(9.7 \%)$ & $5(4-I, 1-U)$ & - & $84 \pm 7$ \\
\hline TAPVD & 32 & $4(12.5 \%)$ & $3(1-P, 2-U)$ & - & $84 \pm 6$ \\
\hline IAA repair & 15 & $1(6.6 \%)$ & $7(6-I, 1-U)$ & $1(14 \%)$ & $73 \pm 11$ \\
\hline $\begin{array}{l}\text { Cavopulmonary } \\
\text { anastomosis }\end{array}$ & 17 & - & $6(5-P, 1-U)$ & - & 100 \\
\hline Miscellaneous & 112 & $22(19.6 \%)$ & $31(12-I, 16-P, \quad 3-U)$ & $8(25.8 \%)$ & $\begin{array}{c}67 \pm 5 \\
(64 \pm 5)\end{array}$ \\
\hline All procedures & 1220 & $85(6.9 \%)$ & 171 (108-I, 26-P,37-U) & $18(10.4 \%)$ & $88 \pm 1$ \\
\hline
\end{tabular}

$A S D$, Atrial septal defect; $A V S D$, atrioventricular septal defect; $V S D$, ventricular septal defect; $P S$, pulmonary stenosis; DORV, double-outlet right ventricle; $T G A$, transposition of the great arteries; TOF, tetralogy of Fallot; $P A$, pulmonary atresia; TAPVD, total anomalous pulmonary venous drainage; IAA, interrupted aortic arch; $I$, inevitable; $P$, planned; $U$, unexpected.

*Figures within brackets denote 20-year survival and are given if adequate number of patients (15) was followed up at 20 years.

Aortic valvotomy (62 patients; age $40 \pm 46$ months); 14 had 1 reoperation and the freedom from reoperation at 10 years was $77 \%$ (Figure 1).

Subaortic stenosis (20 patients; age $96 \pm 42$ months); 4 had 1 reoperation, 2 of which were for repeat resection of subaortic stenosis.

Pulmonary valvotomy/infundibulectomy (66 patients; age 30 \pm 29 months); 8 had 1 reoperation, 5 of which were for recurrent pulmonary stenosis.

$A S D$ (157 patients age; $62 \pm 35$ months); 2 had 1 reoperation, both unrelated to ASD closure.

Partial AVSD (40 patients; age $54 \pm 33$ ); 8 had 1 reoperation, 5 of which were for mitral valve regurgitation. Freedom from reoperation at 10 years was $81 \%$ (Figure 2).

Complete AVSD (44 patients; age $16 \pm 16$ months); 9 had 1 reoperation, 7 of which were for mitral regurgitation. Freedom from reoperation at 10 years was 74\% (Figure 2).

VSD (237 patients; age $17 \pm 18$ months); 13 had 1 reoperation, but only 1 of them was for a recurrent VSD.
VSD and pulmonary stenosis (29 patients; age $64 \pm 52$ months). There were no reoperations in this group.

Double-outlet right ventricle ( 25 patients; age $28 \pm 29$ months); 6 had 1 reoperation, 1 of which was for a residual VSD and 1 related to iatrogenic aortic regurgitation.

Mustard procedure for TGA (56 patients; age $5.7 \pm 4.6$ months); 8 had 1 reoperation, 5 of which were for enlargement of a narrowed baffle. Freedom from reoperation at 10 and 20 years was $85 \%$ (Figure 3 ).

Switch procedure for TGA (38 patients; age $5.7 \pm 4.6$ months); 7 patients had 1 reoperation, 6 of which were for supravalvular pulmonary artery stenosis. Freedom from reoperation at 10 years was $78 \%$ (Figure 3). Survival of patients undergoing Mustard and switch procedures for TGA are shown in Figure 4.

Truncus arteriosus (28 patients; age $2.9 \pm 3$ months); 14 had 1 reoperation, of which 7 were for replacement of the homograft conduit and 4 for truncal valve replacement (Figure 5). 
TABLE 2. Unexpected first reoperations $(n=37)$

\begin{tabular}{|c|c|}
\hline Indication for reoperation & No. \\
\hline \multicolumn{2}{|l|}{ Restenosis } \\
\hline Relief RVOT obstruction & 8 \\
\hline $\begin{array}{l}\text { Pulmonary artery stenosis after switch } \\
\text { procedure }\end{array}$ & 6 \\
\hline Mustard baffle obstruction & 5 \\
\hline Vein stenosis in TAPVD repair & 2 \\
\hline Stenosis after repair of interrupted aortic arch & 1 \\
\hline Ascending aortic stenosis after switch & 1 \\
\hline Early subaortic stenosis & 1 \\
\hline Total & 24 \\
\hline \multicolumn{2}{|l|}{ Technical errors } \\
\hline Residual VSD & 2 \\
\hline Residual VSD and aortic regurgitation & 1 \\
\hline New aortic regurgitation & 2 \\
\hline ASD patch reopened after Fontan & 1 \\
\hline Partial AVSD patch reopened & 1 \\
\hline Stenosis of cavopulmonary anastomosis & 1 \\
\hline Total & 8 \\
\hline \multicolumn{2}{|l|}{ “Bailout” operations } \\
\hline Fontan takedown & 1 \\
\hline $\begin{array}{l}\text { Cavopulmonary anastomosis for failed Ebstein } \\
\text { repair }\end{array}$ & 1 \\
\hline $\begin{array}{l}\text { Shunt for failing pulmonary atresia and VSD } \\
\text { repair }\end{array}$ & 1 \\
\hline Total & 3 \\
\hline \multicolumn{2}{|l|}{ Other } \\
\hline $\begin{array}{l}\text { Mitral valve repair after repair of complete } \\
\text { AVSD }\end{array}$ & 1 \\
\hline $\begin{array}{l}\text { Revision of repair of corrected TGA, pulmonary } \\
\text { atresia, and VSD }\end{array}$ & 1 \\
\hline Total & 2 \\
\hline
\end{tabular}

RVOT, Right ventricular outflow tract; TAPVD, total anomalous pulmonary venous drainage; $V S D$, ventricular septal defects; $A S D$, atrial septal defect; $A V S D$, atrioventricular septal defect; $T G A$, transposition of the great arteries.

Fontan procedure (33 patients; age $96 \pm 39$ months); 8 had 1 reoperation including removal of homografts in 3 patients. Freedom from reoperation at 10 years was $77 \%$.

Tetralogy of Fallot (177 patients; age $18 \pm 13$ months); 19 had 1 reoperation, 9 of which were for pulmonary valve replacement for pulmonary regurgitation. One was for closure of a recurrent VSD and aortic valve repair, and 6 were for relief of right ventricular outflow tract obstruction, 5 of whom had a postoperative right ventricular/left ventricular pressure ratio of less than 0.5 . Freedom from reoperation was $91 \%$ at 10 years and $89 \%$ at 20 years (Figure 6).

Pulmonary atresia and VSD (31 patients; age $44 \pm 45$ months); 5 had 1 reoperation, 2 of which were for insertion of a homograft into the right ventricular outflow tract.

Total anomalous pulmonary venous drainage (32 patients; age $6.5 \pm 6.8$ months); 3 had 1 reoperation, 2 of which were for patch enlargement of stenosed pulmonary veins. The freedom from reoperation was $89 \%$ at 10 years.

Interrupted aortic arch (15 patients; age $2.3 \pm 3.2$ months); 7 had 1 reoperation, only 1 of which was for restenosis of the aorta.

Cavopulmonary anastomosis (17 patients; age $2.3 \pm 3.2$ months); 6 had 1 reoperation, 5 of which were for planned Fontan-type procedures.

Miscellaneous procedures (112 patients; age $43 \pm 47$ months); 31 had undergone reoperation among this large and disparate group.

\section{Discussion}

Reports of complete experience of operations for congenital heart disease are rare, ${ }^{5,6}$ tend to be from the more recent era, and do not have long-term follow-up. This report of 1 surgeon's experience over a 25-year period gives an idea of what can be expected after surgical repair. Although the total of 1220 patients is quite large, the individual numbers of the rarer conditions are small. Most reports of surgical results in the literature tend to relate to the particularly good experience of surgical teams with specific conditions..$^{7-10}$ Thus, a picture is built of what is possible and therefore what should be expected. The reality is in fact different and if the best units reported their entire experience, the whole picture might not be quite the same. Clearly the reasons are multifactorial, and results should be risk-adjusted. ${ }^{11}$ That said, the currently achieved results in many units are extremely good, even with smaller and sicker patients being routinely operated on. This is in part due to increased surgical skill, better myocardial protection, and an improved understanding of anatomy and physiology. Indeed, the advances in cardiology (in particular echocardiography) and intensive care (including support systems), in addition to the vastly superior armamentarium of inotropic and other drugs, have made the management of today's postoperative patients very different from 25 years ago.

In advising parents and patients what to expect in the way of further operations, this article gives a guide, but it must be interpreted with care. For closure of isolated ASDs and VSDs, the likelihood of reoperation is very small. In fact, there was only 1 reoperation for recurrent VSD out of 237 isolated VSD closures. The remaining reoperations in the VSD group were for unrelated factors. Thus, as the likelihood of complications requiring further surgery is so small, most of these patients would be discharged after 1 or 2 follow-up visits. However, virtually all other patients are observed for reasons illustrated in this article.

Of the 108 inevitable reoperations, 11 were for conduit replacement and 50 for valve surgery. It seems unlikely that the need for these procedures will change much in the future. 


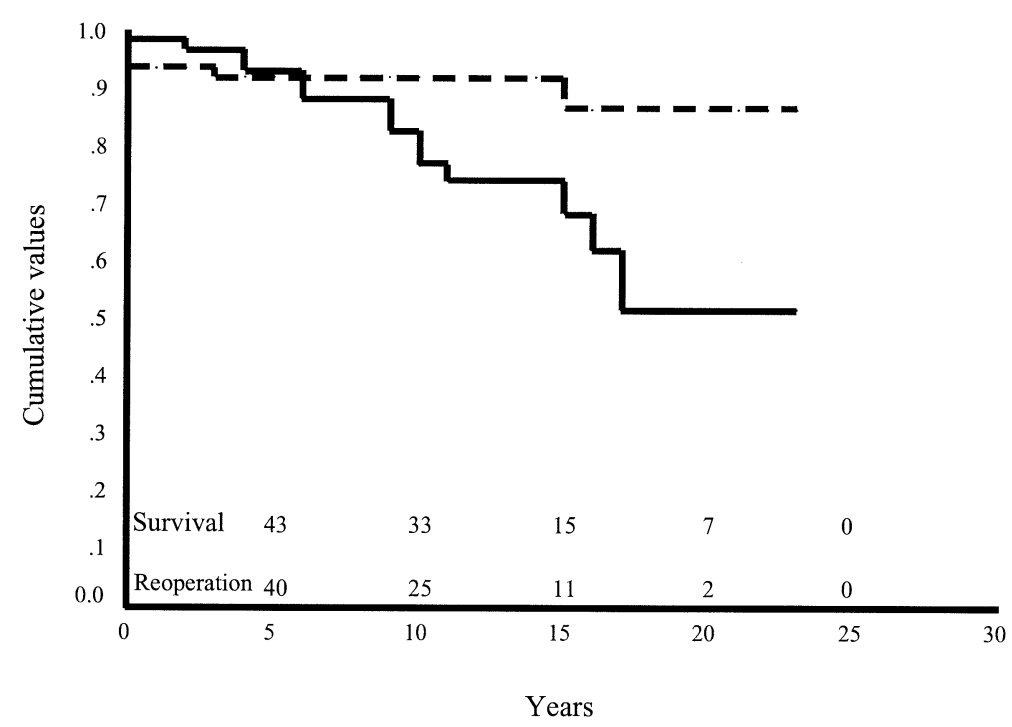

Figure 1. Kaplan-Meier survival (interrupted line) and freedom from any reoperation (continuous line) after aortic valvotomy.

TABLE 3. Kaplan-Meier $10-y e a r$ freedom from reoperation (\%)

\begin{tabular}{|c|c|c|c|c|c|}
\hline Procedure & No. & Any reoperation & $\begin{array}{l}\text { Inevitable } \\
\text { reoperation }\end{array}$ & $\begin{array}{c}\text { Planned } \\
\text { reoperation }\end{array}$ & $\begin{array}{l}\text { Unexpected } \\
\text { reoperation }\end{array}$ \\
\hline Aortic valvotomy & 62 & $77 \pm 7$ & $77 \pm 7$ & 100 & 100 \\
\hline Subaortic stenosis & 20 & $76 \pm 11$ & $76 \pm 11$ & 100 & 100 \\
\hline Pulmonary valvotomy & 66 & $90 \pm 4(86 \pm 5)^{*}$ & $93 \pm 3(89 \pm 4)$ & $97 \pm 2(97 \pm 2)$ & 100 \\
\hline ASD closure & 157 & $99 \pm 0.9(99 \pm 0.9)$ & $99 \pm 0.9(99 \pm 0.9)$ & 100 & 100 \\
\hline Partial AVSD repair & 40 & $81 \pm 7$ & $81 \pm 7$ & 100 & $\begin{array}{c}100 \\
(1-U>10 y)\end{array}$ \\
\hline Complete AVSD repair & 44 & $74 \pm 7$ & $78 \pm 7$ & 100 & $95 \pm 3$ \\
\hline VSD closure & 237 & $95 \pm 1(94 \pm 2)$ & $96 \pm 1(95 \pm 2)$ & 100 & $\begin{array}{c}99 \pm 0.7 \\
(99 \pm 0.7)\end{array}$ \\
\hline VSD and PS & 29 & 100 & 100 & 100 & 100 \\
\hline DORV repair & 25 & $66 \pm 12$ & $79 \pm 11$ & 100 & $92 \pm 5$ \\
\hline Truncus arteriosus repair & 28 & $54 \pm 12$ & $54 \pm 12$ & 100 & 100 \\
\hline Mustard for TGA & 56 & $85 \pm 5(85 \pm 5)$ & $94 \pm 3(94 \pm 3)$ & 100 & $\begin{array}{c}91 \pm 4 \\
(91 \pm 4)\end{array}$ \\
\hline Switch for TGA & 39 & $78 \pm 8$ & 100 & 100 & $78 \pm 8$ \\
\hline Fontan & 33 & $77 \pm 8$ & $84 \pm 8$ & $100(1-P>10 y)$ & $93 \pm 5$ \\
\hline TOF repair & 177 & $91 \pm 2(89 \pm 2)$ & $94 \pm 2(93 \pm 2)$ & 100 & $\begin{array}{c}96 \pm 1 \\
(96 \pm 1)\end{array}$ \\
\hline PA and VSD repair & 31 & $80 \pm 8$ & $83 \pm 8$ & 100 & $97 \pm 3$ \\
\hline TAPVD & 32 & $89 \pm 6$ & 100 & $96 \pm 4$ & $93 \pm 5$ \\
\hline IAA repair & 15 & $45 \pm 14$ & $49 \pm 15$ & 100 & $93 \pm 6$ \\
\hline Cavopulmonary anastomosis & 17 & $43 \pm 17$ & 100 & $46 \pm 18$ & $94 \pm 6$ \\
\hline Miscellaneous & 112 & $61 \pm 6$ & $83 \pm 4$ & $79 \pm 5$ & $97 \pm 2$ \\
\hline All procedures & 1220 & $86 \pm 1$ & $91 \pm 1$ & $98 \pm 0.4$ & $97 \pm 0.5$ \\
\hline
\end{tabular}

$\overline{A S D}$, Atrial septal defect; $A V S D$, Atrioventricular septal defect; $V S D$, ventricular septal defect; $P S$, pulmonary stenosis; DORV, double-outlet right ventricle; $T G A$, transposition of the great arteries; TOF, tetralogy of Fallot; $P A$, pulmonary atresia; $T A P V D$, total anomalous pulmonary venous drainage; IAA, interrupted aortic arch; $I$, inevitable; $P$, planned; $U$, unexpected.

*Figures within brackets denote 20 -year freedom from reoperation and are given if adequate number of patients (15) was followed up at 20 years.

The number of unexpected "first reoperations" at $3.2 \%$ of survivors was reasonably low. Sixteen of the 37 were within 30 days of the first operation. Eight of these unexpected reoperations can be regarded as technical failures (eg, for residual VSDs) and 3 as "bailout" operations (eg, Fontan takedown). In 24 patients various stenoses developed (Table 


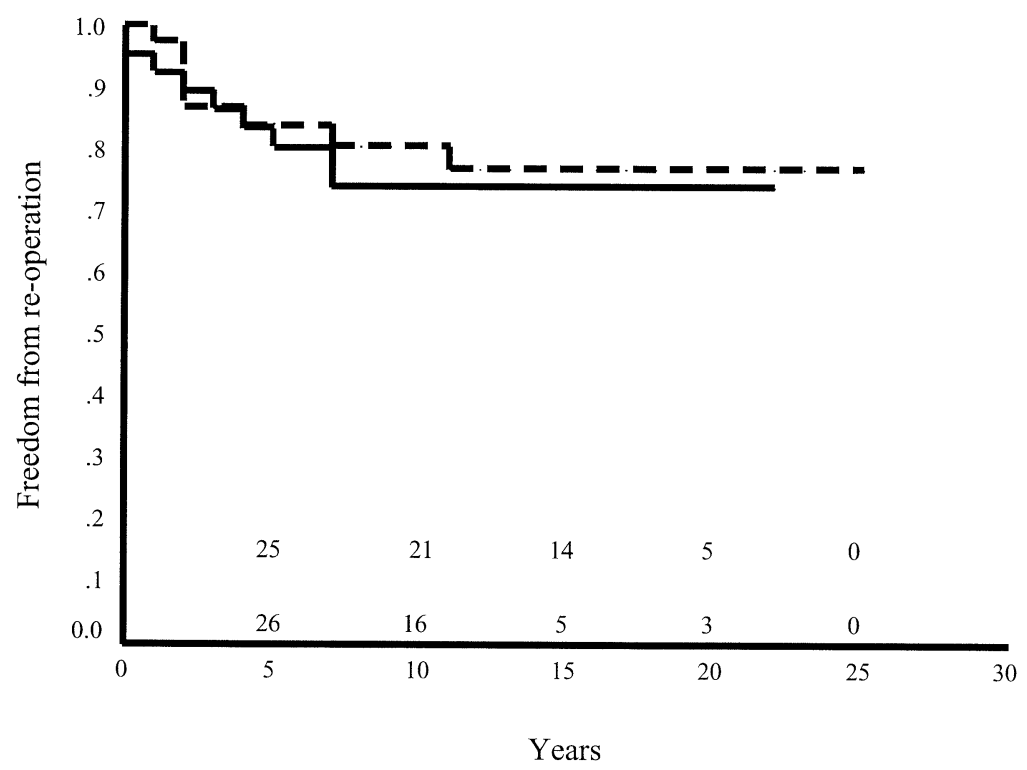

Figure 2. Kaplan-Meier freedom from any reoperation after repair of partial (interrupted line) and complete (continuous line) AVSD.

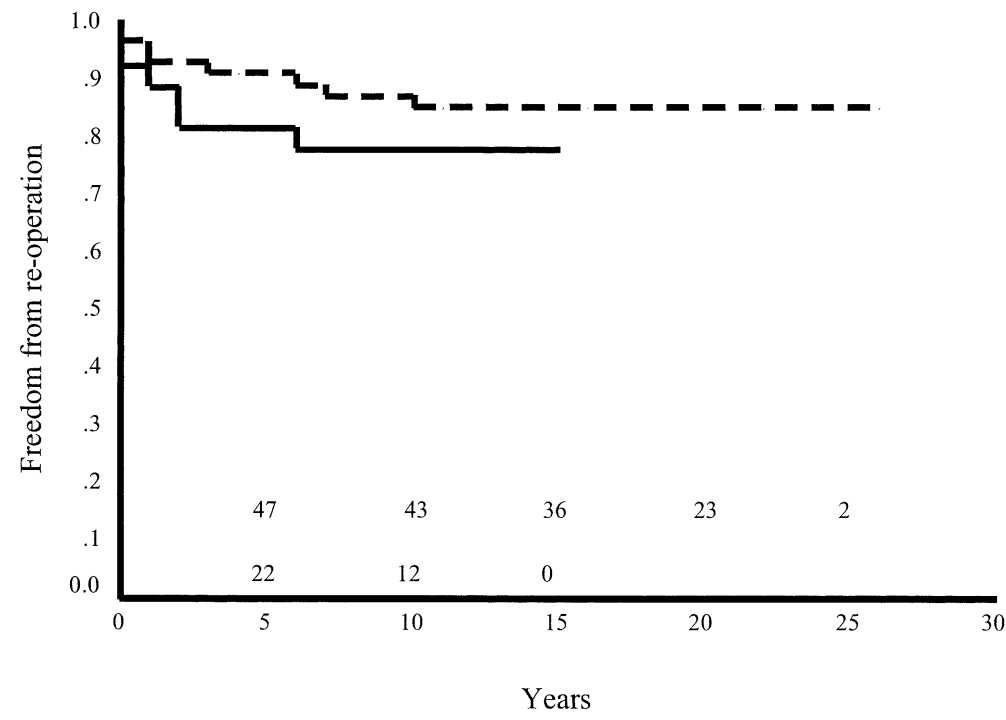

Figure 3. Kaplan-Meier freedom from any reoperation after Mustard (interrupted line) and switch (continuous line) repair of TGA.

2) between 1 day and 7 years postoperatively and 1 patient required mitral valve repair 7 days after repair of CAVSD. Ideally, pulmonary artery stenosis after a switch procedure and Mustard baffle obstruction will become less common. Furthermore, it is perhaps unfair to include recurrent right ventricular outflow tract reconstruction after repair of Fallot's tetralogy occurring more than a year later after a good repair with a low postoperative right ventricular/left ventricular pressure ratio in this group at all. Therefore, the number of unexpected reoperations should fall.
Although the number of second reoperations was small, it is gratifying that the early mortality was less than for first reoperations and that there was no mortality for subsequent reoperation. Clearly one of the risks at reoperation is from bleeding when the sternum is opened. Cannulation of the femoral artery before sternal opening has only been used rarely (eg, when it is known that a conduit is directly behind the sternum).

In advising parents about the likely outcome of an operation, the early mortality and late outcome are equally 


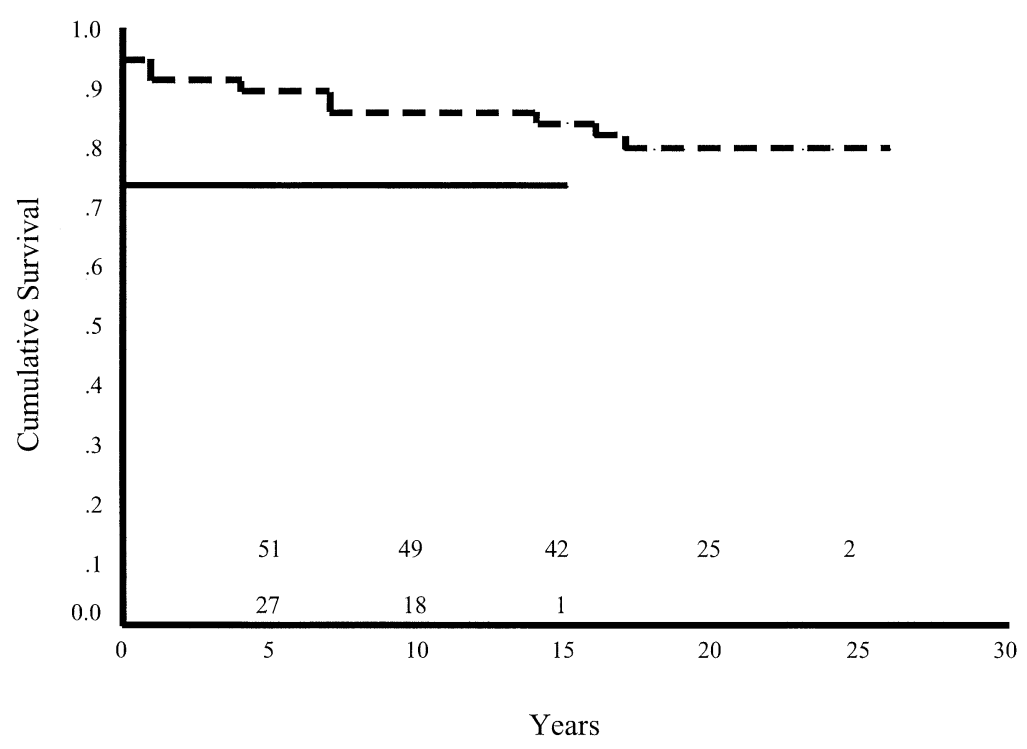

Figure 4. Kaplan-Meier survival after Mustard (interrupted line) and switch (continuous line) repair of TGA.

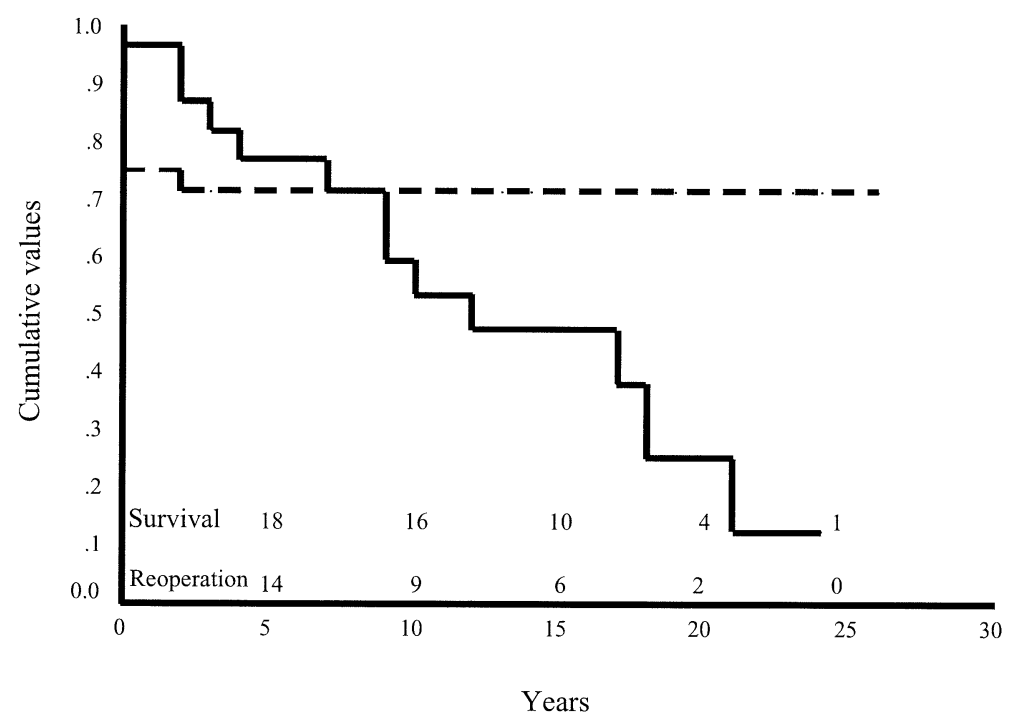

Figure 5. Kaplan-Meier survival (interrupted line) and freedom from any reoperation (continuous line) after repair of truncus arteriosus.

important. Therefore, although this report is chiefly concerned with reoperations, unlike Lange's series, ${ }^{12}$ we have included the early mortality. Clearly the patient who has a suboptimal operation and dies will not have postoperative complications requiring reoperation. Therefore, to just report reoperations without the early mortality does not give the whole picture.

Patients undergoing aortic valvotomy are almost certain to need further surgery, and the parents should be warned accordingly. However, the freedom from operation at 10 years in this series was 77\% even though 33 (53\%) of the patients undergoing aortic valvotomy were less than 1 year of age. Because of the good results with open surgical valvotomy, we still opt for this mode of treatment rather than balloon valvotomy. We suggest that this results in less early regurgitation and, because of a precise splitting of fused cusps, delays the eventual reoperation, at which time an adult-size valve can usually be inserted. ${ }^{13}$ Occasionally it is possible to perform repair rather than replacement at reoperation. ${ }^{14}$ Although the occurrence of severe aortic regurgitation in an infant is an indication for a Ross procedure, none has been done in this series. When aortic valve 


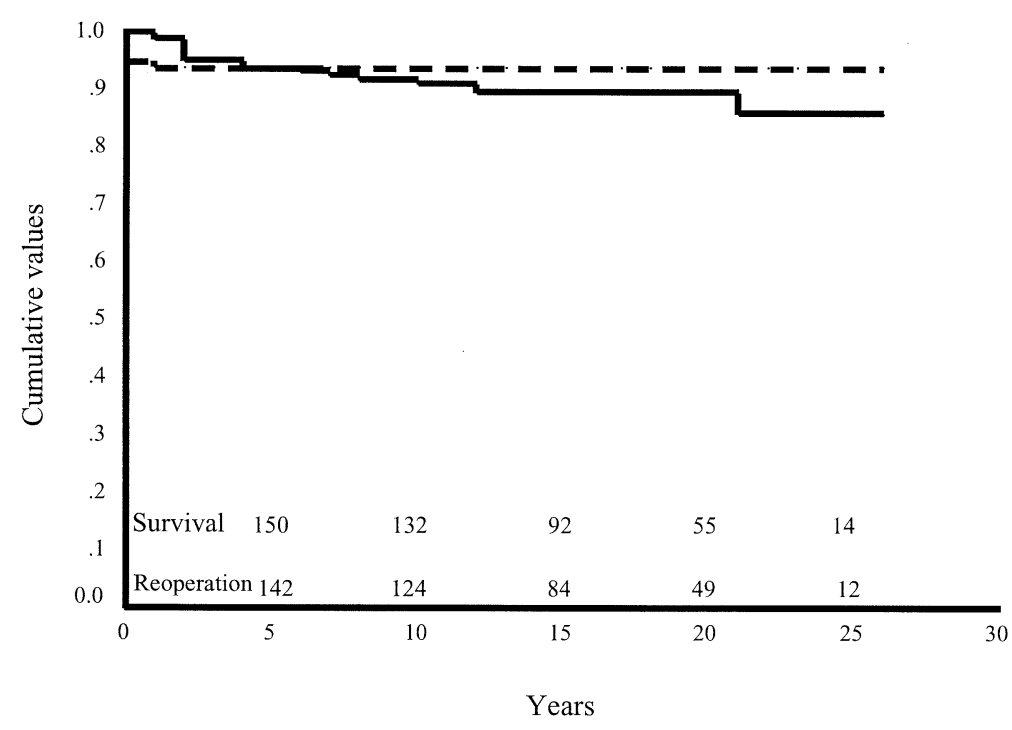

Figure 6. Kaplan-Meier survival (interrupted line) and freedom from any reoperation (continuous line) after repair of tetralogy of Fallot.

replacement has been necessary, we have favored mechanical valves. ${ }^{15}$

The patients undergoing repair of PAVSD and CAVSD had a relatively high incidence of subsequent mitral valve regurgitation, which is related to leaving the cleft unsutured, as recommended by Carpentier. ${ }^{16}$ We now suture it, which should result in less late mitral regurgitation, and parents can be advised accordingly.

The $25 \%$ mortality for truncus arteriosus compares favorably with that in the United Kingdom, ${ }^{17}$ which was $41 \%$ between 1978 and 2000. We used large homografts whenever possible and the mean interval before replacement was 12.7 years. ${ }^{18}$ This compares favorably with the 6.2 years reported by Lange and coworkers. ${ }^{12}$ In comparison, only 2 of 28 survivors after repair of pulmonary atresia and VSD have had their homografts replaced, possibly because larger valves were inserted.

The Mustard procedure was the treatment of choice for TGA until about 1986 when the switch procedure was introduced, although they overlapped for a few years. It is an interesting example of a technique that at that time had a low mortality but with an inevitable falloff in years to come, being superseded by an operation that at the time had a high mortality but ideally a trouble-free late outcome. As Figures 3 and 4 show, in this small experience, the lines have still not met, mainly because the early experience with the switch procedure in this series had a high mortality by today's standards and a relatively high incidence of pulmonary artery stenosis.

Of those patients undergoing a Fontan procedure before 1990 , only $26 \%$ are alive without having further surgery, but since 1990 , with the total cavopulmonary connection ${ }^{2}$ and subsequently extracardiac conduit, ${ }^{19}$ there have been no early or late deaths among 20 patients. This is a good example of how a planned reoperation (after a cavopulmonary anastomosis) has improved survival despite increasing the total number of operations.

In Fallot's tetralogy we have always had a policy of correcting rather than palliating where possible. During the period of this study, the principal surgeon has only palliated 10 infants. It was interesting that 5 patients developed recurrent right ventricular outflow tract obstruction (even when the immediate postoperative right ventricular/left ventricular pressure ratio was less than 0.5 ) and this was usually within 2 years. However, many patients will have received transannular patches and inevitably will have pulmonary regurgitation, which may necessitate the insertion of a valve in the pulmonary region in due course. However, in 89 infants among this group undergoing correction of Fallot's tetralogy, although $77 \%$ had a transannular patch, $95 \%$ were free of pulmonary valve replacement 20 years later. ${ }^{20}$

The miscellaneous group is so diverse that comment is difficult. So many complicated patients fall into this group that it is not surprising that the mortality was high at $20 \%$ and the reoperation rate also high at $28 \%$.

In conclusion, although obviously the longer a group of patients is observed, the more reoperations they will need, it is encouraging that only $15 \%$ of operative survivors required reoperation up to 26 years postoperatively. This is clearly dependent on the case mix but gives a good idea of the likelihood of reoperation when it comes to giving advice to parents. Also, some of the operations have been superseded or changed considerably, which ideally will result in fewer reoperations being required in the future. 
This study has shown that in probably less than $1 \%$ of operations were there avoidable surgical errors resulting in reoperation. However, errors may be concealed in the early mortality, which is why it has also been reported here.

The overall $86 \%$ 20-year Kaplan-Meier survival in this group is encouraging for a group containing patients operated on many years ago. The early mortality has declined so much in most centers that the overall survival must improve, but most patients should be observed to detect any need for reoperation, which can be achieved with low mortality. However, the inevitable group of reoperations will probably not reduce much and we should continue to consider operations for congenital heart disease as repairs rather than corrections.

\section{References}

1. Monro JL, Shore G. A colour atlas of cardiac surgery. Congenital heart disease. London: Wolfe Medical Publications; 1984. p. 79-187.

2. de Leval MR, Kilner P, Gewillig M, Bull C. Total cavopulmonary connection: a logical alternative to atriopulmonary connection for complex Fontan operations. J Thorac Cardiovasc Surg. 1988;96:68295.

3. Trusler GA, Isukawa T. Interrupted aortic arch and ventricular septal defect: direct repair through a median sternotomy incision in a 13day-old infant. J Thorac Cardiovasc Surg. 1975;69:126-31.

4. Monro JL, Bunton RW, Sutherland GR, Keeton BR. Correction of interrupted aortic arch. J Thorac Cardiovasc Surg. 1989;98:421-427.

5. Moller J. Paediatric cardiac care consortium 1984-1995. Armonk (NY): Futura Publishing; 1998

6. Hannan EL, Racz M, Kavey RE, Quaegebeur JM, Williams R. Pediatric cardiac surgery: the effect of hospital and surgeon volume on in-hospital mortality. Pediatrics. 1998;101:963-69.

7. Quaegebeur JM, Rohmer J, Ottenkamp J, et al. The arterial switch operation: an eight year experience. J Thorac Cardiovasc Surg. 1986; 92:361-84.

8. Bove EL. Current status of staged reconstruction for hypoplastic left heart syndrome. Pediatr Cardiol. 1998;19:308-15.

9. Stark J, Gallivan S, Lovegrove J, et al. Mortality rates after surgery for congenital heart defects in children and surgeons' performance. Lancet. 2000;355:1004-8.

10. Thompson LD, McElhinney DB, Reddy M, Petrossian E, Silverman NH, Hanley FL. Neonatal repair of truncus arteriosus: continuing improvement in outcomes. Ann Thorac Surg. 2001;72:391-5.

11. Jenkins KJ, Gauvreau K, Newburger JW, Spray TL, Moller JH, Lezzoni L. Consensus-based method for risk adjustment for surgery for congenital heart disease. J Thorac Cardiovasc Surg. 2002;123: $110-8$.

12. Lange R, Schreiber C, Gunther T, et al. Results of biventricular repair of congenital cardiac malformations: definitive corrective surgery? Eur J Cardiothorac Surg. 2001;20:1207-13.

13. Alexiou C, Chen Q, Langley SM, et al. Is there still a place for open surgical valvotomy in the management of aortic stenosis in children? The view from Southampton. Eur J Cardiothorac Surg. 2001;20:23946.

14. Tolan MJ, Daubeney PE, Slavik Z, Keeton BR, Salmon AP, Monro JL. Aortic valve repair of congenital stenosis with bovine pericardium. Ann Thorac Surg. 1997;63:465-9.

15. Alexiou C, McDonald A, Langley SM, Dalrymple-Hay MJR, Haw MP, Monro JL. Aortic valve replacement in children: are mechanical prostheses a good option? Eur J Cardiothorac Surg. 2000;17:125-33.

16. Carpentier A. Surgical anatomy and management of the mitral component of atrioventricular canal defects. In: Anderson RH, Shinebourne EA, editors. Paediatric cardiology. London: Churchill Livingstone; 1977. p. 477-90.
17. English TAH, Bailey AR, Dark JF, Williams WG. The UK cardiac surgical register 1977-82. BMJ. 1984;289:1205-8.

18. Alexiou C, Keeton BR, Salmon AP, Monro JL. Repair of truncus arteriosus in early infancy with antibiotic sterilized aortic homografts. Ann Thorac Surg. 2001;71(Suppl):S371-4.

19. Marcelletti C, Corno A, Giannico S, Marino B. Inferior vena cavapulmonary artery extracardiac conduit: a new form of right heart bypass. J Thorac Cardiovasc Surg. 1990;100:228-32.

20. Alexiou C, Mahmoud H, Al-Khaddour A, et al. Outcome after repair of tetralogy of Fallot in the first year of life. Ann Thorac Surg. 2001;71:494-500.

\section{Appendix}

\section{Procedures Performed in Fewer Than 15 Patients}

Mitral valve disease (repair) (10)

Pulmonary atresia with intact ventricular septum (9)

Hypoplastic heart syndrome (8)

Univentricular heart and other (13)

Aortic valve disease (aortic valve replacement) (8)

Mitral valve disease (mitral valve replacement) (8)

Major aortopulmonary collaterals with other anomalies (5)

Supravalvular aortic stenosis (5)

Absent pulmonary valve syndrome (4)

Anomalous origin of coronary arteries (4)

Hemianomalous pulmonary venous drainage (3)

Hypoplastic aortic arch (3)

Tricuspid regurgitation (including Ebstein anomaly) (5)

Cor triatriatum (3)

Other (22)

Total (111)

\section{Discussion}

Dr Marshall L. Jacobs (Philadelphia, Pa). It is a particular pleasure for me to have the opportunity to discuss Mr Monro's paper, as I am one of more than a dozen members of this Association who had the opportunity to train with $\mathrm{Mr}$ Monro at the Wessex Cardiothoracic Center in Southampton.

What has been presented here this afternoon is the product of an archival database reflecting 25 years of experience in the management of infants and children with congenital heart disease. Although it was perhaps less apparent 25 years ago, the importance of this archival process is all too apparent today. Quality assurance and quality improvement, outcomes research in general, are mere phrases without the discipline and the diligence to prospectively record accurate clinical data. For his pioneering effort in this regard with respect to congenital heart disease, Mr Monro deserves a great deal of credit.

This analysis focuses on issues of reoperation and survival. Entry into the overall data set required that a child underwent a primary repair with CPB. Reoperations were assigned to 1 of 3 categories: inevitable, planned, or unexpected.

In some instances, as, for example, with respect to partial AVSD, changes in surgical strategy led to a significant reduction in the need for secondary operations. In other instances, such as the move toward staging of single ventricle repairs, a strategy that virtually ensures the need for secondary operations, resulted in a significant survival advantage.

Mr Monro, I have a few questions: 